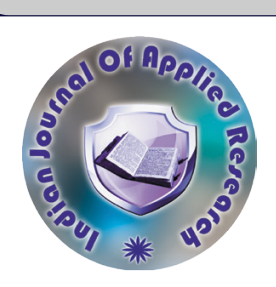

Dr.C.Amirtha*
Gynaecology

\title{
MASSIVE HAEMOPERITONIUM FROM A RUPTURED CORPUS LUTEAL
} CYST

\section{Dr.Vidhya}

Post-graduate ,Department of obstetrics and gynaecology, Sree Balaji Medical College and Hospital, Chennai. * Corresponding Author

\section{ABSTRACT}

Assistant professor ,Department of obstetrics and gynaecology, Sree Balaji Medical College and Hospital,Chennai. course varies from no symptoms or signs to severe peritoneal irritations and even life-threatening shock (1). Women of reproductive age are at risk of ruptured corpus luteum with hemoperitoneum. Prompt recognition and treatment is required for this condition because late diagnosis can be life threating for the patient. This case we are going to discuss, a 26 years married women, Para- 2 Live- 2 ,presented to the emergency room with acute pelvic pain. Right adnexal mass massive haemoperitonium was found on USG and CT abdomen. Emergency laparotomy was performed and proceeded with right salphingo -oophorectomy.Histopathological examination revealed right ruptured haemorrhagic corpus luteal cyst (functional cyst) to be the cause for massive haemoperitonium. Ruptured corpus luteal cyst can be a differential diagnosis for acute abdominal pain in women of reproductive age group.

\section{KEYWORDS : Acute pelvic pain, women of reproductive age ,haemoperitonium ,ruptured corpus luteal cyst} \section{INTRODUCTION}

Even though ovarian cyst rupture is a self-limiting event with conservative management, it occasionally requires surgical intervention when accompanied by hemodynamic instability, severe persistent pain, diagnostic uncertainty, or large amount of hemoperitoneum $(2,3)$. Although any functional ovarian cyst can present as a intraperitoneal haemorrhage, the increased vascularity of the ovary in the luteal phase may increase the risk of rupture and bleeding of the corpus luteal cyst (1). Although several previous studies have reported a rate of surgery for ruptured corpus luteal cysts with hemoperitoneum as high as $80 \%(2,4)$, conservative management is usually performed.

\section{CASE REPORT}

A 26 years married parous, not sterilized women presented to the emergency room with complaints of severe lower abdominal pain since early morning, sudden in onset, persistant, increasing in severity ,not relieved on taking rest and medications, not radiating.it was associated with 4 episodes of vomiting. Her last menstrual period was 30 days ago. Her previous cycles were normal in flow, frequency and duration. No H/O bleeding per vaginum and other gynaecological complaints. No H/O urinary symptoms.

On arrival general examination patient was conscious vital signs were BP-100/60 Pulse rate- 110/min, SPO2-98\% in room air.on abdominal examination there was diffuse remarkable tenderness throughout the abdomen,mild distension was present. There was significant guarding and rigidity. on per vaginal examination cervix was soft, os closed, uterus retroverted, uterus bulky, movement of cervix was painfull and forniceal tenderness was present.UPT was found to be negative. Ultrasound abdomen showed right adnexal mass of sixe 5 and $4 \mathrm{~cm}$ and massive haemoperitonium in the peritoneal cavity. CT screening was done which confirmed right adnexal mass and massive haemoperitonium extending to the Morrison's pouch .initial laboratory investigations revealed $\mathrm{Hb}$ : 6.6 grams \%.coagulation profile was normal. Blood availability was checked and kept ready.

Emergency laparotomy was performed in view of intraperitoneal bleed and haemodynamic instability. On exploration: (1)Massive haemoperitonium was noted to about 1.1 litres with clots. (2) Right haemorrhagic cyst, a small rent was present with active bleed (3) As the patient has completed the family right salphingo oophorectomy was done. (4) 2 units of packed cell transfusion was given intraoperatively. (5)Opposite tubes and ovaries were normal. Retroperitoneum was opened to rule out retroperitoneal collections. (5)Her postoperative period was uneventfull.(6)Specimen was sent for HPE. (7)Histopathological examination revealed haemorrhagic corpus luteal cyst.

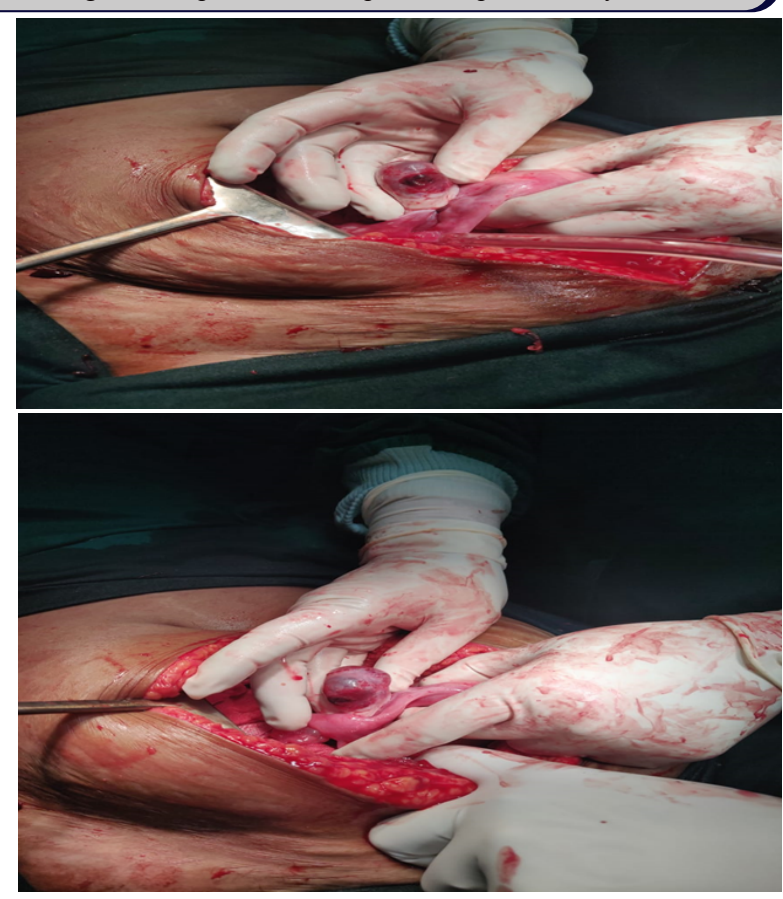

\section{DISCUSSION}

The corpus luteum is a temporary hormone secreting remnant of a mature ovarian follicle after it ruptures to release an ovum into the fallopian tube. Its main function is to secrete progesterone to maintain early pregnancy till placenta is developed by 8-10 weeks. If fertilization does not occur, the corpus luteum involutes several days after ovulation (corpus albicans), shrinks and stops producing progesterone, resulting in menstruation. However, the corpus luteum may fill with blood or other fluids forming a cyst and rupture [5]. Abdominal pain caused by a ruptured corpus luteum cyst is a common complaint in a woman of childbearing age. The complaints are usually self-limited to pain. Only in rare cases they can lead to massive hemoperitoneum requiring surgical management.

Spontaneous massive hemoperitoneum secondary to a hemorrhagic corpus luteum cyst is an exceedingly rare, but potentially lifethreatening presentation.

Increased vascularity in the ovary during luteal phase and pregnancy which may rapid enlargement, ruptue and bleeding from the functional cysts. While some hemorrhage associated with ovarian cyst rupture has unclear etiology, there are recognized risk factors. These include abdominal trauma and anticoagulation therapy 5]. The right ovary 
seems predisposed to rupture more than the left one, as seen in both of our cases [6]. One of the possible explanations for this predisposition is the protection of left ovary from trauma by the cushioning of the rectosigmoid colon [7]. Typically at the time of rupture, there may be sharp and sudden onset of pain, which has no typical characteristics. Blood loss can vary from very little bleeding to hypovolemic shock [7]

Operative findings of ruptured corpus luteal cysts often reveal that the rupture involved the arteriole of the ovary, which produces active bleeding with resultant hemoperitoneum(1)

Management of corpus luteum haemorrhage is conservative or surgical $[16,17,18]$. Therapy for ruptured corpus luteal cysts with intraabdominal hemorrhage must be tailored to the patient.

Ultrasonic evidence of large amounts of peritoneal fluid and severe pain is indication for operative intervention [16-18]. In our case since there was massive haemoperitonium exploratory laparotomy was done.In corpus luteum haemorrhage, oophorectomy is rarely necessary [18]. This form of minimally invasive surgery provides potential benefits for improved cosmetic appearance, shorter hospital stay, reduced postoperative pain, and earlier postoperative return to daily activities. In patients with recurrent corpus luteum haemorrhage, oral contraceptives are used to suppress ovulation *(17)

In the last years more and more surgical interventions such as fulguration, suture, biopsy and salpingoophorectomy are performed through the laparoscope. There is no conclusive evidence that laparoscopic handling of the ovaries results in considerably fewer adhesions. When more extensive intervention is needed the question arises whether laparotomy is preferable to laparoscopy combined with colpotomy as was suggested by Freistadt 1985 [8].

\section{CONCLUSION}

Ruptured haemorrhagic corpus luteal cyst can be the cause for acute pelvic pain. This can lead to acute massive haemoperitonium and can be life threatening.In such condition life saving emergency surgical management is required.

\section{REFERENCES}

1. Teng SW, Tseng JY, Chang CK, Li CT, Chen YJ, Wang PH. Comparison of laparoscopy and laparotomy in managing hemodynamically stable patients with ruptured corpus luteum with hemoperitoneum. J Am Assoc Gynecol Laparosc. 2003;10:474-477. [PubMed] [Google Scholar]

2. Raziel A, Ron-El R, Pansky M, Arieli S, Bukovsky I, Caspi E. Current management of ruptured corpus luteum. Eur J Obstet Gynecol Reprod Biol. 1993;50:77-81. [PubMed] [Google Scholar]

3. Bottomley C, Bourne T. Diagnosis and management of ovarian cyst accidents. Best Pract Res Clin Obstet Gynaecol. 2009;23:711-724. [PubMed] [Google Scholar]

4. Ho WK, Wang YF, Wu HH, Tsai HD, Chen TH, Chen M. Ruptured corpus luteum with hemoperitoneum: case characteristics and demographic changes over time. Taiwan J Obstet Gynecol. 2009;48:108-112. [PubMed] [Google Scholar]

5. Niswender GD, Juengel JL, Silva PJ, Rollyson MK, McIntush EW (2000) Mechanisms controlling the function and life span of the corpus luteum. Physiol Rev 80(1): 1-29.

6. Tang LC, Cho HK, Chan SY, Wong VC (1985) Dextropreponderance of corpus luteum rupture. Aclinical study. J Reprod Med 30(10): 764-768.

7. Hallatt JG, Steele CH, Snyder M (1984) Ruptured corpus luteum with hemoperitoneum: Hallatt JG, Steele CH, Snyder M (1984) Ruptured corpus luteu
a study of 173 surgical cases. Am J Obstet Gynecol 149(1): 5-9.

16. Hoffman R, Brenner B (2009) Corpus luteum hemorrhage inwomen with bleeding disorders. Womens Health (Lond) 5(1): 91-95.

17. Payne JH, Maclean RM, Hampton KK, Baxter AJ, Makris M (2007) Haemoperitoneum associated with ovulation in women with bleeding disorders: the case for conservative management and the role of the contraceptive pill. Haemophilia 13(1): 93-97.

18. Jamal A, Mesdaghinia S (2002) Ruptured corpus luteum cysts and anticoagulant therapy. Int J Gynaecol Obstet 76(3): 319-320. 